\title{
Hepatitis B Virus Infection in B-Cell Non-Hodgkin's Lymphoma, and Effect of Entecavir in Prophylactic Antiviral Therapy
}

\author{
Jinjing Chen', Haizhen Yi' ${ }^{2}$, Hong Cen ${ }^{3}$, Wei Yan² \\ ${ }^{1}$ Department of Hematology, Guangxi Guigang People's Hospital, Guigang, China \\ ${ }^{2}$ Department of Medical Oncology, Guangxi Guigang People's Hospital, Guigang, China \\ ${ }^{3}$ Department of Medical Oncology, Guangxi Cancer Hospital, Nanning, China \\ Email: *jijing_chen228815@163.com
}

Received 22 February 2016; accepted 27 March 2016; published 30 March 2016

Copyright (C) 2016 by authors and Scientific Research Publishing Inc.

This work is licensed under the Creative Commons Attribution International License (CC BY). http://creativecommons.org/licenses/by/4.0/

(c) () Open Access

\begin{abstract}
Background: specialized studies on hepatitis B virus (HBV) infection and B-NHL (B-cell Non-Hodgkin's Lymphoma) are limited, as well as prophylactic antiviral therapy for B-NHL patients with HBV infection who are receiving anticancer chemotherapy. This study aims to investigate the association between HBV infection and B-NHL, and to evaluate the effect of prophylactic antiviral therapy for HBV-infected B-NHL patients. Study design: A retrospective, case-control study was performed. The study group included 420 patients with B-NHL who were consecutively diagnosed from May 2003 to October 2013 (age range, 14 - 71 years), and the control group included 1280 Chinese residents in Guangxi who participated in the Health Survey (age range, 18 - 74 years). We compared the prevalence rate of $\mathrm{HBV}$ infection and clinic-pathologic characteristics between the two groups. The prevalence rate of HBV infection in our study was $34.7 \%(146 / 420)$, higher than the prevalence rate of $13.9 \%(178 / 1280)$ in the general population $(P<0.001)$. Among $146 \mathrm{~B}-\mathrm{NHL}$ patients who received anticancer chemotherapy, 104 patients $(71.2 \%)$ received prophylactic antiviral therapy. Conclusion: This study provides evidence that HBV may play an important role in development of B-NHL. Entecavir maybe the better antiviral drugs than Lamivudine, and antiviral therapy is maintained more than 6 months that maybe the optimal duration of prophylactic antiviral therapy. But further investigation should be conducted for determination of optimal duration and monitoring of antiviral therapy.
\end{abstract}

\section{Keywords}

Hepatitis B infection, B-NHL, Prevalence, Prophylactic Antiviral Therapy

\footnotetext{
${ }^{*}$ Corresponding author.
}

How to cite this paper: Chen, J.J., Yi, H.Z., Cen, H. and Yan, W. (2016) Hepatitis B Virus Infection in B-Cell Non-Hodgkin's Lymphoma, and Effect of Entecavir in Prophylactic Antiviral Therapy. Health, 8, 495-503. 


\section{Introduction}

Hepatitis B virus (HBV) was discovered in 1966 [1], which infected 350 million people worldwide [2]. It leads to 340,000 liver cancer cases and 500,000 to 1.2 million liver-related deaths each year [2] [3]. China is one of the endemic areas of chronic HBV infection, HBV infection is a common disease, and there are approximately 170 million carriers in China [4]. The incidence of Non-Hodgkin's Lymphoma is increasing rapidly in China, with an annual rise of $1 \%$ to $4 \%$ [5]. At present, NHL ranks the 11th most common cancer [6].

Notably, a number of studies have suggested that chronic HBV infection may act as an etiologic factor in NHL [7]-[10]. Hepatitis B virus (HBV) and hepatitis C virus (HCV) are hepatotropic viruses, they can replicate in lymphoid cell [11] [12]. Previous studies have demonstrated an association between hepatitis C virus (HCV) infection and B-NHL [13] [14]. It has also been proposed that hepatitis B virus (HBV) may be an etiologic agent of Non-Hodgkin's Lymphoma (NHL) [15]-[17], but relatively few studies have investigated the association between HBV infection and B-NHL.

As far as our information goes, in hematologic malignancy, such as NHL and leukemia, anticancer systemic chemotherapy can induce HBV replication and reactivation of hepatitis B, which may lead to hepatitis flare and even hepatic failure [18]-[21]. Some studies have indicated that Lamivudine can reduce the incidence of HBV reactivation [22]. Therefore, prophylactic antiviral therapy has been recommended before or at initiation of chemotherapy for all HBsAg-positive NHL patients undergoing systemic chemotherapy [23], but evidence from controlled trials of this prophylactic antiviral therapy is limited [24].

The aim of this study is to discuss the association between HBV infection and B-NHL using a case-control design, on the other hand, we want to evaluate the optimal duration and monitoring of antiviral therapy against HBV for HBsAg-positive B-NHL patients who have undergone anti-cancer chemotherapy.

\section{Materials and Methods}

\subsection{Patients}

There are 2 patient groups in this case-control study, one study group and one control group. Among 431 patients who were diagnosed with B-NHL.

At Guangxi Guigang People’s Hospital, China, from May 2003 to October 2013, patients were required to have histological confirmed B-NHL. 11 patients who were not tested for HBV surface antigen (HBsAg) were excluded. Therefore, 420 B-NHL patients were included in the case group (B-NHL group). A total of $1280 \mathrm{~Pa}-$ tients in the control group were chosen randomly from among individuals who participated in the Health Survey were diagnosed with non-hematologic malignancy and non-primary liver cancer (Figure 1). Patients were regarded as chronic HBV carriers if it was positive for HBsAg for at least 6 months. The type and stage of B-NHL were diagnosed basing on the World Health Organization (WHO)/Revised European-American Lymphoma classification system. All patients provided written, informed consent to have a test for HBV infection at their first visit.

\subsection{Methods}

Subjects were enrolled by using the clinical data ware system of the hospital. We adopted a retrospective, casecontrol design to investigate the association between HBV and B-NHL. All of the patients were tested for antibody against HBsAg (anti-HBs), anti-HBs and serum ALT level, Serum HBV DNA level was detected using the Branched DNA detection method. Among the 146 patients were treated with curative intent using CHOP-based (cyclophosphamide, doxorubucin, vincristine and prednisolone) regimens, except 5 patients were treated with curative intent using hyper CVAD. Retrospective analysis of electronic medical records was executed for appraisal of the application rate and the effect of prophylactic antiviral therapy for HBsAg-positive B-NHL patients who received chemotherapy. HBV reactivation was defined as increased viral replication of at least 10 -fold from that of the baseline level. Hepatitis flare was defined as a greater than 3-fold increase of serum ALT level that exceeded $100 \mathrm{IU} / \mathrm{L}$. HBV-related hepatitis flare was defined as hepatitis flare due to HBV reactivation [25]-[27].

The dose of prophylactic antiviral therapy was using Lamivudine $100 \mathrm{mg}$ or Entecavir $0.5 \mathrm{mg}$ once daily. Patients treated with prophylactic Entecavir divide into 3 groups (prophylactic antiviral therapy continued for a further 3 or 6 or more than 6 months beyond the date of completion of chemotherapy). How to use prophylactic antiviral therapy was depended on each clinician. 


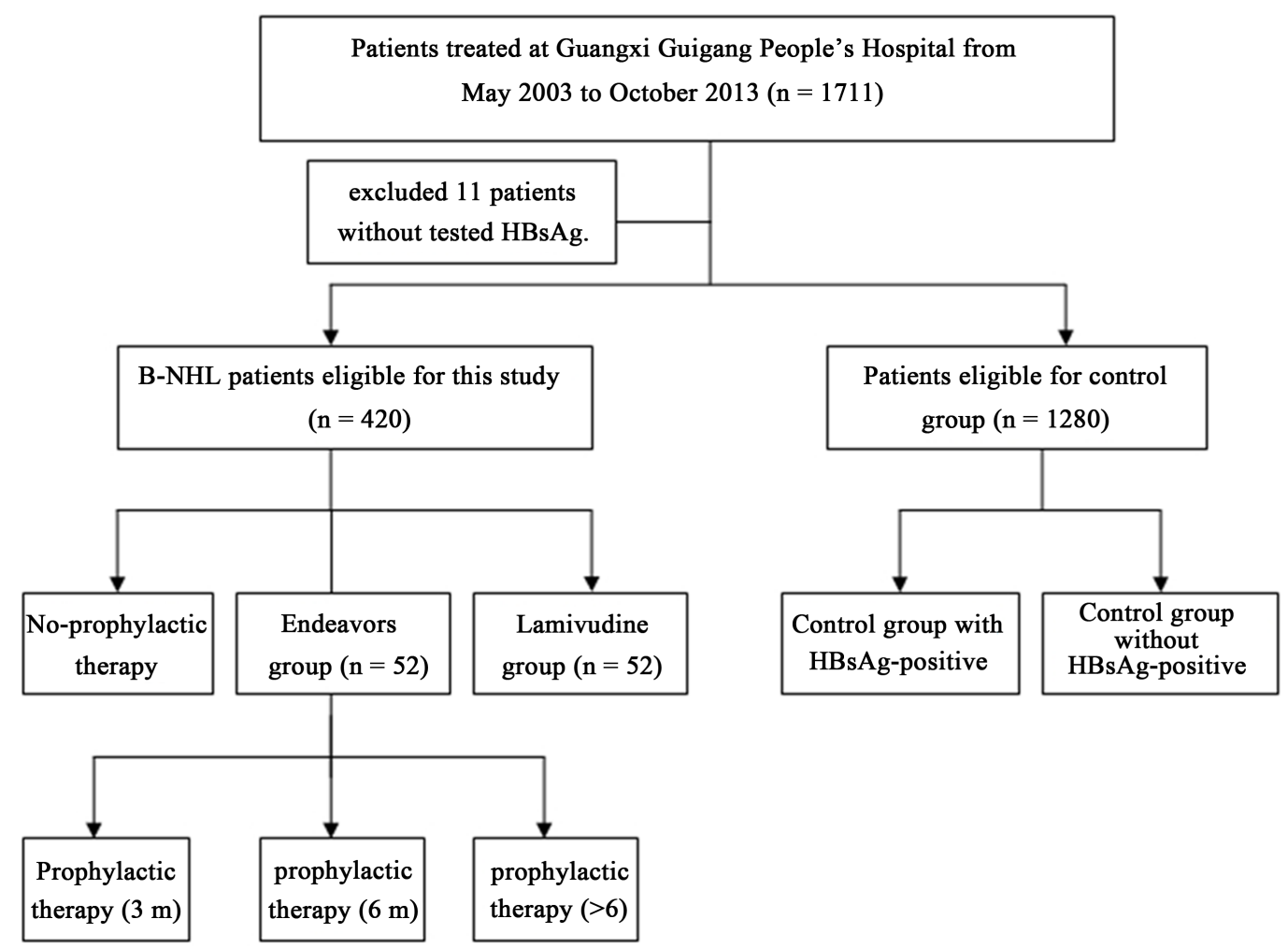

Figure 1. Flowchart of study design. A total of 1711 patients met the enrollment criteria. Among 431 patients who were diagnosed with B-NHL from May 2003 to October 2013, 11 patients who were not tested for HBV surface antigen (HBsAg) were excluded. 420 B-NHL patients were included in the case group (B-NHL group). A total of 1280 Patients in the control group were chosen randomly from among individuals who participated in the Health Survey were diagnosed with non-hematologic malignancy and non-primary liver cancer. Footnote: n, number of patients.

\subsection{Statistics}

Our study expressed data as the median and range or mean as appropriate. Comparison of HBsAg prevalence between the B-NHL group and the control group was presented, comparative analyses of clinicopathologic characteristics between the two groups were performed using the $t$ test or chi-squared test for continuous or categorical variables respectively. The Statistical Program for Social Science (SPSS 17.0 for windows; SPSS Inc., Chicago, IL, USA) was used in performance of all statistical analyses, and $p$-value less than 0.05 was considered significant.

\section{Results}

In the study group, there were 420 Patients in B-NHL group and 1280 Patients in the control group, which including 178 patients with HBsAg-positive. All of 420 patients were diagnosed with B-NHL, 146 patients were positive for HBsAg. The prevalence of HBV infection in the B-NHL group was higher than in the general population (34.7\% vs. $13.9 \%, P<0.001$ ), in sex group, prevalence was statistically higher in patients with B-NHL than in the general population $(P<0.001)$ (Table 1$)$. There was no Statistical differences for HBsAg-positive patients between the B-NHL group presented and the general population $(p=0.08)$ (Table 2).

Among the 146 HBsAg-positive B-NHL patients, 104 patients underwent anticancer chemotherapy, and 52 patients (67.2\%) received prophylactic antiviral therapy with Lamivudine and 52 patients used Entecavir. The remaining 42 patients who had not received prophylactic antiviral therapy, 42 patients without prophylactic antiviral therapy were treated with curative intent using CHOP-based (cyclophosphamide, doxorubucin, vincristine and prednisolone) regimens, during anticancer chemotherapy; there was 22 occurrence of hepatitis, including HBV-related hepatitis in 21 patients and Interrupt of planned chemotherapy in 7 patients. 104 patients with prophylactic antiviral therapy, the group using Lamivudine there are 12 occurrence of hepatitis, including HBV- 
Table 1. HBV Prevalence among patients in B-NHL cases and controls.

\begin{tabular}{cccc}
\hline & B-NHL group & Control group & $P$-Value \\
\hline No. of patients & 420 & 1280 & $<0.001$ \\
HBsAg-positive, $\%$ & $146(34.7)$ & $178(13.9)$ & $<0.001$ \\
Sex (HBsAg-positive, \%) & & & 0.001 \\
In male & $284(112,39.4)$ & $582(96,14.1)$ & $18-74$ \\
In female & $136(34,25)$ & $598,13.7)$ & \\
Age, y & $14-71$ & 40 & \\
Rang & 38 & & \\
Median &
\end{tabular}

Table 2. Clinical characteristics of B-NHL group VS control group with HBsAg-positive with HBsAg-positive.

\begin{tabular}{cccc}
\hline & B-NHL group & Control group & $P$-Value \\
\hline HBsAg-positive & 146 & 178 & \\
Age, y & $14-52$ & $18-74$ & $<0.001$ \\
Rang & 27 & 28 & $<0.001$ \\
Median & 112 & 96 & 0.08 \\
Sex & 34 & 82 & \\
In male & 140 & 176 & \\
In female & 5 & 2 & \\
Underlying liver status & 1 & 0 & \\
Normal liver function tests & & & \\
Chronic hepatitis & & & \\
Liver cirrhosis & & & \\
\hline
\end{tabular}

related hepatitis in 10 patients and Interrupt of planned chemotherapy in 2 patients, in another group of using Entecavir there are 2 occurrence of hepatitis, including HBV-related hepatitis in 1 patients and interrupt of planned chemotherapy in 0 patient. By receiving prophylactic antiviral therapy may reduce the incidence of hepatitis especially using Entecavir $(P<0.001)$ (Table 3$)$.

During prophylactic antiviral therapy, Patients treated with prophylactic Entecavir divide into 3 groups (prophylactic antiviral therapy continued for a further 3 or 6 or more 6 months beyond the date of completion of chemotherapy), antiviral therapy was maintained for more than 6 months maybe the optimal duration of prophylactic antiviral therapy $(P<0.001)$ (Table 4$)$.

\section{Discussion}

The main finding of the our study was that the prevalence of hepatitis B infection in B-NHL patients was significantly higher than that in the control group, suggesting a significant role of HBV infection in B-NHL. Moreover, prophylactic antiviral therapy was administered to all of the chronic HBV-infected B-NHL patients receiving cancer chemotherapy. By using antiviral therapy (Lamivudine and Entecavir), the occurrence of hepatitis flare might be significantly reduced than no antiviral therapy (23.1\% VS 3.85\% VS $52.4 \%, P<0.001$ ) (Table 3 ). More importantly, disruption to planned chemotherapy was dramatically reduced (3.85\% VS 16.7\%). It should be noted that Entecavir for prophylactic antiviral therapy might reduce the incidence of hepatitis; the difference in length of time led to different results, using Entecavir for antiviral therapy by more than 6 months might reduce the occurrence of hepatitis flare than 6 or 3 months (Table 4). 
Table 3. No prophylactic therapy vs. Lamivudine and Entecavir prophylactic therapy in HBV-infected patients receiving chemotherapy $(P<0.05)$.

\begin{tabular}{|c|c|c|c|c|}
\hline & $\begin{array}{l}\text { No prophylactic } \\
\text { therapy }\end{array}$ & $\begin{array}{c}\text { Prophylactic } \\
\text { therapy (lamivudine) }\end{array}$ & $\begin{array}{c}\text { Prophylactic } \\
\text { therapy (entecavir) }\end{array}$ & $P$-value \\
\hline \multicolumn{5}{|l|}{ Histology } \\
\hline B-NHL & 42 & 52 & 52 & \\
\hline \multicolumn{5}{|l|}{ ECOG } \\
\hline 0 or 1 & 41 & 50 & 48 & 0.15 \\
\hline$>1$ & 1 & 2 & 4 & \\
\hline \multicolumn{5}{|l|}{ Chemotherapy regimen } \\
\hline СHOP & 42 & 49 & 52 & 0.33 \\
\hline Hyper CVAD & 0 & 3 & 2 & \\
\hline Normal baseline ALT & 38 & 52 & 52 & 0.61 \\
\hline No. of patients HBV DNA monitored & 42 & 52 & 52 & \\
\hline Incidence of hepatitis (Total) & $22(52.4 \%)$ & $12(23.1 \%)$ & $2(3.85 \%)$ & $\begin{aligned} P & =0.000^{\mathrm{a} 1} \\
P & =0.006^{\mathrm{a} 2} \\
P & =0.000^{\mathrm{a} 3} \\
P & =0.01^{\mathrm{a} 4}\end{aligned}$ \\
\hline HBV-reactivation & $21(50.0 \%)$ & $10(19.2 \%)$ & $1(1.92 \%)$ & $\begin{array}{l}P=0.000^{\mathrm{a} 1} \\
P=0.001^{\mathrm{a} 2} \\
P=0.000^{\mathrm{a} 3} \\
P=0.013^{\mathrm{a} 4}\end{array}$ \\
\hline Interrupt of planned chemotherapy & $7(16.7 \%)$ & $2(3.85 \%)$ & $0(0 \%)$ & \\
\hline
\end{tabular}

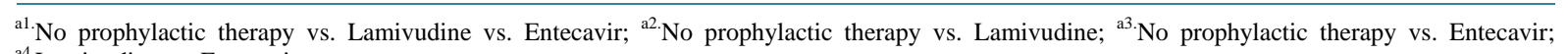

${ }^{\mathrm{a} 4}$ Lamivudine vs. Entecavir

Table 4. Entecavir prophylaxis 3 months vs. Entecavir prophylaxis 6 and more than 6 monthins in HBV-infected patients receiving chemotherapy.

\begin{tabular}{|c|c|c|c|}
\hline & $\begin{array}{l}\text { Prophylactic therapy } \\
\text { (3 months) }\end{array}$ & $\begin{array}{c}\text { Prophylactic } \\
\text { therapy (6 months) }\end{array}$ & $\begin{array}{l}\text { Prophylactic therapy } \\
\text { (>6 months) }\end{array}$ \\
\hline \multicolumn{4}{|l|}{ Chemotherapy regimen } \\
\hline CHOP & 20 & 20 & 12 \\
\hline Hyper CVAD & 2 & 0 & 0 \\
\hline Normal baseline ALT & 19 & 20 & 12 \\
\hline No. of patients HBV DNA monitored & 20 & 20 & 12 \\
\hline Incidence of hepatitis (Total) & $2(50 \%)$ & 0 & 0 \\
\hline HBV-related hepatitis & 1 & 0 & 0 \\
\hline
\end{tabular}

Several case-control studies had shown that chronic HBV infection increased the risk for development of B-NHL; these results were compatible with those of our study [28] [29]. Moreover, some studies showed that high HBV prevalence was observed not only in B-cell NHL but also in the T-cell NHL group. Kang et al. in Korea demonstrated an association of HBV infection with B-cell NHL by using a study design similar to ours [30] [31]. But previous studies had not found a significant association between HBV infection and B-cell NHL, so in this study, we only discussed association between HBV infection and B-NHL.

Compare with the association between hepatitis C viruses (HCV) and B-NHL, studies of the mechanism link- 
ing HBV to B-NHL induction had been limited. As far as our information goes, HBV could bind to peripheral blood mononuclear cells (PBMCs) via the pre S1 protein, compared with T cells, B lymphocytes and monocytes were found to bind viral particles more efficiently [25] [32]. Which had been confirmed in animal models that HBV DNA integration in PBMCs and hepatocytes was demonstrated in HBV carriers and anti-HBc only positive individuals [25] [33] [34]? HBV genes were transcribed in PBMCs in vivo, and then viral replication and transcription in PBMCs [35], so the lymphoid system was an important reservoir of HBV [36]. By the analogy with HBV, antigenic stimulation or polyclonal activation may promote chronic B cell proliferation, direct infection of HBV and the oncogenic role of integrated HBV DNA in B-lymphoid cells that may be the major mechanisms. Further study in this field should be warranted [25].

Hepatitis B virus reactivation during chemotherapy increased risks of liver-related morbidity and mortality [37]-[40]. Therefore, recent guidelines recommend routine testing for HBsAg before anti-cancer chemotherapy; HBsAg-positive patients should acceptance prophylactic antiviral therapy for prevention of HBV reactivation [25] [41]. Li et al. reported a threefold decrease in the incidence of hepatitis and significantly less disruption to chemotherapy, compared to a historical control group of $116 \mathrm{HBV}$-infected patients not treated with prophylactic Lamivudine [31]. Similarly, in another case-control study, HBV reactivation occurred in none of the 16 patients who received prophylactic Lamivudine, whereas seven of 19 patients in the control group experienced HBV reactivation [31] [39]. As well as our study had showed that, all B-NHL patients were screened for HBsAg before initiation of treatment, and all HBV-infected B-NHL patients received prophylactic antiviral therapy, using Lamivudine, before or at initiation of anti-cancer chemotherapy. Our results showed that there was 12 occurrence of hepatitis flare during antiviral therapy by using Lamivudine but 2 in the group of using Entecavir. after withdrawal of antiviral drug in Three months, by using Entecavir, about half of the patients developed hepatitis flare, in prophylactic therapy 6 or More than 6 months, there were not withdrawal hepatitis. Our results were compatible with previous studies [25] [31]. Baseline high HBV DNA level or presence of HBeAg and underlying liver cirrhosis were predictive factors for hepatitis flare [31] [42]. In this study, antiviral therapy was maintained for 3 or 6 months after finish cytotoxic chemotherapy, for 6 months was according to the American guidelines [43]. Recently, European guidelines have recommended maintenance of prophylactic antiviral therapy for 12 months after completion of systemic chemotherapy [44], while Korean Association recommends 3 months of maintenance of antiviral drug [45]. This study suggested maintenance of prophylactic antiviral therapy for at least 6 months after completion of chemotherapy. Because of the probability of Lamivudine resistance, further studies should be warranted on the optimal duration of prophylactic antiviral therapy and selection of the optimal antiviral drug [31], Entecavir maybe one of the better drug than Lamivudine in our study. Although in HBsAg-positive DLBCL patients undergoing R-CHOP chemotherapy, Entecavir is more effective than Lamivudine in preventing hepatitis B reactivation, however, it is not yet widely used in Asia, In China, At present, two important classes of antiviral drugs are available for treatment of CHB: interferons (IFNs) and nucleos(t)ide analogs (NAs). The available NAs include Entecavir (ETV), Lamivudine (LAM), adefovir dipivoxil (ADV), and telbivudine (LDT), all of them are recommended as first-line anti-HBV therapies (Chinese Society of Hepatology and Chinese Society of Infectious Diseases, 2011). However, the selection of treatments with a high barrier to resistance is not always possible in China. Thus, antiviral resistance and suboptimal virological responses have begun to emerge as important challenges for clinicians due to poor patient compliance, the pharmacologic properties of the particular drug(s), and individual genetic variations occurring during NA therapy, also because of cost.

Several limitations should be mentioned in our study, we included a single center, retrospective design, and we frequently omitted monitoring of HBV DNA level among HBV carrier patients receiving anticancer chemotherapy for B-NHL. Our study demonstrated occurrence of HBV reactivation and hepatitis flare in isolated anti-HBc positive patients. But most of the HBsAg negative B-NHL patients did not undergo testing for anti-HBc or HBV DNA, which precluded analysis of HBV reactivation in the setting of occult HBV infection.

In conclusion, this is a case-control study on the association between HBV infection and B-cell Non-Hodgkin’s Lymphoma; HBV may play a pathogenic role in development of B-NHL. Prophylactic antiviral therapy was administered during chemotherapy to almost all of the B-NHL patients with HBV infection showing good response to antiviral therapy, and Entecavir maybe the better the better drug than Lamivudine for prophylactic antiviral therapy. Our findings warrant further investigation, including the determination of optimal duration and monitoring of prophylactic antiviral therapy is warranted. 


\section{Acknowledgements}

My deepest gratitude goes first and foremost to Professor Hong Cen for helping me work out my problems during the difficult course of the thesis.

\section{Funding}

None.

\section{Conflict of Interest}

No conflict of interest to declare.

\section{References}

[1] Lee, W.M. (1997) Hepatitis B Virus Infection. The New England Journal of Medicine, 337, 1733-1745. http://dx.doi.org/10.1056/NEJM199712113372406

[2] Liaw, Y.F. and Chu, C.M. (2009) Hepatitis B Virus Infection. The Lancet, 373, 582-592. http://dx.doi.org/10.1016/S0140-6736(09)60207-5

[3] Parkin, D.M. (2006) The Global Health Burden of Infection-Associated Cancers in the Year 2002. International Journal of Cancer, 118, 3030-3044. http://dx.doi.org/10.1002/ijc.21731

[4] Li, Y.H., He, Y.F. and Jiang, W.Q. (2006) Lamivudine Prophylaxis Reduces the Incidence and Severity of Hepatitis in Hepatitis B Virus Carriers Who Receive Chemotherapy for Lymphoma. Cancer, 106, 1320-1325. http://dx.doi.org/10.1002/cncr.21701

[5] Muller, A.M., Ihorst,G. and Mertelsmann, R. (2005) Epidemiology of Non-Hodgkin’s Lymphoma (NHL): Trends, Geographic Distribution, and Etiology. Annals of Hematology, 84, 1-12. http://dx.doi.org/10.1007/s00277-004-0939-7

[6] Parkin, D.M., Bray, F. and Ferlay, J. (2005) Global Cancer Statistics, 2002. CA: A Cancer Journal for Clinicians, 55, 74-108. http://dx.doi.org/10.3322/canjclin.55.2.74

[7] Cucuianu, A., Patiu, M. and Duma, M. (1999) Hepatitis B and C Virus Infection in Romanian Non-Hodgkin’s Lymphoma Patients. British Journal of Haematology, 107, 353-356. http://dx.doi.org/10.1046/j.1365-2141.1999.01692.x

[8] Kim, J.H., Bang, Y.-J., Park, B.J., Yoo, T., Kim, C.W., Kim, T.Y., Heo, D.S., Lee, H.-S. and Kim, N.K. (2002) Hepatitis B Virus Infection and B-Cell Non-Hodgkin’s Lymphoma in a Hepatitis B Endemic Area: A Case-Control Study. Japanese Journal of Cancer Research, 93, 471-477. http://dx.doi.org/10.1111/j.1349-7006.2002.tb01280.x

[9] He, H., Zhai, M. and Zhang, D. (2003) Clinical Significance of Detecting Serum Label of Hepatitis B Virus in NHL Patients. Journal of Chinese Clinical Medicine, 4, 8-10.

[10] Kuniyoshi, M., Nakamuta, M. and Sakai, H. (2001) Prevalence of Hepatitis B or C Virus Infections in Patients with Non-Hodgkin's Lymphoma. Journal of Gastroenterology and Hepatology, 16, 215-219. http://dx.doi.org/10.1046/j.1440-1746.2001.02406.X

[11] Yoffe, B., Noonan, C.A., Melnick, J.L. and Hollinger, F. (1986) Hepatitis B Virus DNA in Mononuclear Cells and Analysis of Cell Subsets for the Presence of Replicative Intermediates of Viral DNA. The Journal of Infectious Diseases, 153, 471-477. http://dx.doi.org/10.1093/infdis/153.3.471

[12] Bronowicki, J.P., Loriot, M.A., Thiers, V., Grignon, Y., Zignego, A.L. and Bréchot, C. (1998) Hepatitis C Virus Persistence in Human Hematopoietic Cells Injected into SCID Mice. Hepatology, 28, 211-218. http://dx.doi.org/10.1002/hep.510280127

[13] Musto, P. (2002) Hepatitis C Virus Infection and B-Cell non-Hodgkin’s Lymphomas: More than a Simple Association. Clinical Lymphoma, 3, 150-160. http://dx.doi.org/10.3816/CLM.2002.n.021

[14] Negri, E., Little, D., Boiocchi, M., La Vecchia, C. and Franceschi, S. (2004) B-Cell Non-Hodgkin’s Lymphoma and Hepatitis C Virus Infection: A Systematic Review. International Journal of Cancer, 111, 1-8. http://dx.doi.org/10.1002/ijc.20205

[15] Dal Maso, L. and Franceschi, S. (2006) Hepatitis C Virus and Risk of Lymphoma and Other Lymphoid Neoplasms: A Meta-Analysis of Epidemiologic Studies. Cancer Epidemiology, Biomarkers \& Prevention, 15, 2078-2085. http://dx.doi.org/10.1158/1055-9965.EPI-06-0308

[16] Dal Maso, L., Talamini, R., Montella, M., Crovatto, M. and Franceschi, S. (2004) Hepatitis B and C Viruses and Hodgkin Lymphoma: A Case-Control Study from Northern and Southern Italy. Haematologica, 89, e141-e142.

[17] Gentile, G., Mele, A., Monarco, B., Vitale, A., Pulsoni, A., Visani, G., Castelli, G., Rapicetta, M., Verani, P., Martino, 
P. and Mandelli, F. (1996) Hepatitis B and C Viruses, Human T-Cell Lymphotropic Virus Types I and II, and Leukemias: A Case-Control Study. The Italian Leukemia Study Group. Cancer Epidemiology, Biomarkers \& Prevention, 5, 227-230.

[18] Kwag, J.Y., Jung, S.H., Kang, Y.K., Han, C.J., Kim, Y.C. and Lee, J.O. (2000) Acute Exacerbation of Hepatitis in Hepatitis B Virus Carriers with Non-Hodgkin's Lymphoma after Chemotherapy Korean. Journal of Gastroenterology, 35, 64-72.

[19] Ku, B.K., Hahn, J.S., Hahn, K.H., Lee, S.T., Suh, H.C. and Kwon, K.H. (1997) Clinical Outcome of the HBsAg Positive Malignant Lymphoma Patients Following Anticancer Chemotherapy. The Korean Journal of Medicine, 52, 542549.

[20] Lalazar, G., Rund, D. and Shouval, D. (2007) Screening, Prevention and Treatment of Viral Hepatitis B Reactivation in Patients with Haematological Malignancies. British Journal of Haematology, 36, 699-712. http://dx.doi.org/10.1111/j.1365-2141.2006.06465.x

[21] Lau, G.K. (2008) Hepatitis B Reactivation after Chemotherapy: Two Decades of Clinical Research. Hepatology International, 2, 152-162. http://dx.doi.org/10.1007/s12072-008-9056-3

[22] Ziakas, P.D., Karsaliakos, P. and Mylonakis, E. (2009) Effect of Prophylactic Lamivudine for Chemotherapy-Associated Hepatitis B Reactivation in Lymphoma: A Meta-Analysis of Published Clinical Trials and a Decision Tree Addressing Prolonged Prophylaxis and Maintenance. Haematologica, 94, 998-1005. http://dx.doi.org/10.3324/haematol.2009.005819

[23] Lau, G.K., Yiu, H.H., Fong, D.Y., Cheng, H.C., Au, W.Y. and Lai, L.S. (2003) Early Is Superior to Deferred Preemptive Lamivudine Therapy for Hepatitis B Patients Undergoing Chemotherapy. Gastroenterology, 125, 1742-1749. http://dx.doi.org/10.1053/j.gastro.2003.09.026

[24] Artz, A.S., Somerfield, M.R., Feld, J.J., Giusti, A.F., Kramer, B.S. and Sabichi, A.L. (2010) American Society of Clinical Oncology Provisional Clinical Opinion: Chronic Hepatitis B Virus Infection Screening in Patients Receiving Cytotoxic Chemotherapy for Treatment of Malignant Diseases. Journal of Clinical Oncology, 28, 3199-3202. http://dx.doi.org/10.1200/JCO.2010.30.0673

[25] Kim, Y.M., Jeong, S.-H., Kim, J.-W., Lee, S.H., Hwang, J.H., Park, Y.S., Kim, N., Lee, J.S., Kim, H.Y. and Lee, D.H. (2011) Chronic Hepatitis B, Non-Hodgkin's Lymphoma, and Effect of Prophylactic Antiviral Therapy. Journal of Clinical Virology, 51, 237-241.

[26] Lok, A.S. and McMahon, B.J. (2001) Chronic Hepatitis B. Hepatology, 34, 1225-1241. http://dx.doi.org/10.1053/jhep.2001.29401

[27] Hsu, C., Hsiung, C.A., Su, I.J., Hwang, W.S., Wang, M.C. and Lin, S.F. (2008) A Revisit of Prophylactic Lamivudine for Chemotherapy-Associated Hepatitis B Reactivation in Non-Hodgkin's Lymphoma: A Randomized Trial. Hepatology, 47, 844-853. http://dx.doi.org/10.1002/hep.22106

[28] Engels, E.A., Cho, E.R. and Jee, S.H. (2010) Hepatitis B Virus Infection and Risk of Non-Hodgkin Lymphoma in South Korea: A Cohort Study. The Lancet Oncology, 11, 827-834. http://dx.doi.org/10.1016/S1470-2045(10)70167-4

[29] Yood, M.U., Quesenberry Jr., C.P., Guo, D., Caldwell, C., Wells, K., Shan, J., Sanders, L., Skovron, M.L., Iloeje, U. and Manos, M.M. (2007) Incidence of Non-Hodgkin's Lymphoma among Individuals with Chronic Hepatitis B Virus Infection. Hepatology, 46, 107-112. http://dx.doi.org/10.1002/hep.21642

[30] Kang, J., Cho, J.H., Suh, C.W., Lee, D.H., Oh, H.B. and Sohn, Y.H. (2010) High Prevalence of Hepatitis B and Hepatitis C Virus Infections in Korean Patients with Hematopoietic Malignancies. Annals of Hematology, 90, 159-164. http://dx.doi.org/10.1007/s00277-010-1055-5

[31] Lim, S.-T., Fei, G., Quek, R., Lim, L.-C., Lee, L.-H., Yap, S.-P., Loong, S. and Tao, M. (2007) The Relationship of Hepatitis B Virus Infection and Non-Hodgkin's Lymphoma and Its Impact on Clinical Characteristics and Prognosis. European Journal of Haematology, 79, 132-137. http://dx.doi.org/10.1111/j.1600-0609.2007.00878.x

[32] Pontisso, P., Morsica, G., Ruvoletto, M.G., Zambello, R., Colletta, C. and Chemello, L. (1991) Hepatitis B Virus Binds to Peripheral Blood Mononuclear Cells via the Pre S1 Protein. Journal of Hepatology, 12, 203-206. http://dx.doi.org/10.1016/0168-8278(91)90939-9

[33] Murakami, Y., Minami, M., Daimon, Y. and Okanoue, T. (2004) Hepatitis B Virus DNA in Liver, Serum, and Peripheral Blood Mononuclear Cells after the Clearance of Serum Hepatitis B Virus Surface Antigen. Journal of Medical Virology, 72, 203-214. http://dx.doi.org/10.1002/jmv.10547

[34] Umeda, M., Marusawa, H., Seno, H., Katsurada, A., Nabeshima, M. and Egawa, H. (2005) Hepatitis B Virus Infection in Lymphatic Tissues in Inactive Hepatitis B Carriers. Journal of Hepatology, 42, 806-812. http://dx.doi.org/10.1016/j.jhep.2005.01.016

[35] Stoll-Becker, S., Repp, R., Glebe, D., Schaefer, S., Kreuder, J. and Kann, M. (1997) Transcription of Hepatitis B Virus in Peripheral Blood Mononuclear Cells from Persistently Infected Patients. Journal of Virology, 71, 5399-5407. 
[36] Pontisso, P., Vidalino, L., Quarta, S. and Gatta, A. (2008) Biological and Clinical Implications of HBV Infection in Peripheral Blood Mononuclear Cells. Autoimmunity Reviews, 8, 13-17. http://dx.doi.org/10.1016/j.autrev.2008.07.016

[37] Hoofnagle, J.H., Dusheiko, G.M. and Schafer, D.F. (1982) Reactivation of Chronic Hepatitis B Virus Infection by Cancer Chemotherapy. Annals of Internal Medicine, 96, 447-449. http://dx.doi.org/10.7326/0003-4819-96-4-447

[38] Rossi, G., Pelizzari, A., Motta, M. and Puoti, M. (2001) Primary Prophylaxis with Lamivudine of Hepatitis B Virus Reactivation in Chronic HbsAg Carriers with Lymphoid Malignancies Treated with Chemotherapy. British Journal of Haematology, 15, 58-62. http://dx.doi.org/10.1046/j.1365-2141.2001.03099.x

[39] Vassiliadis, T., Garipidou, V. and Tziomalos, K. (2005) Prevention of Hepatitis B Reactivation with Lamivudine in Hepatitis B Virus Carriers with Hematologic Malignancies Treated with Chemotherapy-A Prospective Case Series. American Journal of Hematology, 80, 197-203. http://dx.doi.org/10.1002/ajh.20471

[40] Yeo, W., Chan, P.K. and Ho, W.M. (2004) Lamivudine for the Prevention of Hepatitis B Virus Reactivation in Hepatitis B Santigen Seropositive Cancer Patients Undergoing Cytotoxic Chemotherapy. Journal of Clinical Oncology, 22, 927-934. http://dx.doi.org/10.1200/JCO.2004.05.161

[41] Dai, M.S., Chao, T.Y., Kao, W.Y., Shyu, R.Y. and Liu, T.M. (2004) Delayed Hepatitis B Virus Reactivation after Cessation of Preemptive Lamivudine in Lymphoma Patients Treated with Rituximab plus CHOP. Annals of Hematology, 83, 769-774. http://dx.doi.org/10.1007/s00277-004-0899-y

[42] Hui, C.K., Cheung, W.W., Au, W.Y., Lie, A.K., Zhang, H.Y. and Yueng, Y.H. (2005) Hepatitis B Reactivation after Withdrawal of Pre-Emptive Lamivudine in Patients with Haematological Malignancy on Completion of Cytotoxic Chemotherapy. Gut, 54, 1597-1603. http://dx.doi.org/10.1136/gut.2005.070763

[43] Lok, A.S. and McMahon, B.J. (2004) Chronic Hepatitis B: Update of Recommendations. Hepatology, 39, 857-861. http://dx.doi.org/10.1002/hep.20110

[44] European Association for the Study of the Liver (2009) EASL Clinical Practice Guidelines: Management of Chronic Hepatitis B. Journal of Hepatology, 50, 227-242. http://dx.doi.org/10.1016/j.jhep.2008.10.001

[45] Lee, K.S. and Kim, D.J. (2007) Management of Chronic Hepatitis B. Korean Journal of Hepatology, 13, 447-488. http://dx.doi.org/10.3350/kjhep.2007.13.4.447 